Importer and Producer Petroleum Taxation: A Geo-Political Model

Jon Strand 

IMF Working Paper

Fiscal Affairs Department

\title{
Importer and Producer Petroleum Taxation: A Geo-Political Model
}

\author{
Prepared by Jon Strand ${ }^{1}$
}

Authorized for distribution by Isaias Coelho

February 2008

\begin{abstract}
This Working Paper should not be reported as representing the views of the IMF.

The views expressed in this Working Paper are those of the author(s) and do not necessarily represent those of the IMF or IMF policy. Working Papers describe research in progress by the author(s) and are published to elicit comments and to further debate.

We derive non-cooperative Nash equilibrium (NE) importer and exporter petroleum excise taxes given full within-group tax coordination, but no coordination between groups, assuming that importers do not produce and exporters do not consume petroleum, and petroleum consumption causes a global externality. The aggregate NE tax is found to consist of an externality component and an optimal tariff component, and exceeds the standard Pigou tax. The environmental component in isolation is however less than the Pigou tax. With Stackelberg tax setting, the leader's tax is higher than in the Ne, and the follower's tax lower, and the overall tax higher. We show that importers prefer to set a tax instead of an import quota, since exporters' optimal response to a quota is a higher tax. An optimal cap-and-trade scheme will thus fare worse than an optimal tax scheme for importers, and will imply greater petroleum consumption and carbon emissions. When exporters behave as a cartel satisfying demand at a fixed export price, exporters' optimal tax is higher, while importers tax rule is Pigouvian. Exporters then gain at the expense of importers.
\end{abstract}

JEL Classification Numbers:H23; Q31; Q41; Q54

Keywords: Petroleum taxes; environmental externalities; Nash equilibrium; Stackelberg equilibrium; cap-and-trade schemes

Author's E-Mail Address:jstrand@imf.org

\footnotetext{
${ }^{1}$ I thank, without implicating, Robert Flood, Michael Keen, and seminar participants in the IMF for helpful comments to previous versions.
} 


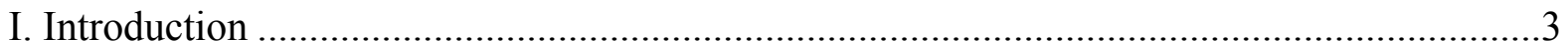

II. Nash Equilibrium Importer Petroleum Taxes .............................................................5

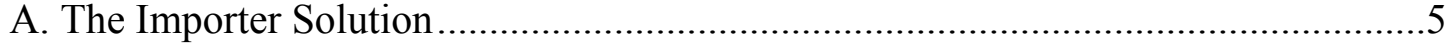

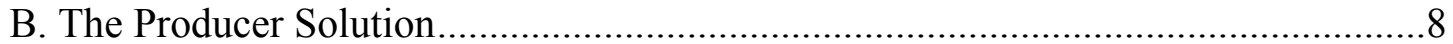

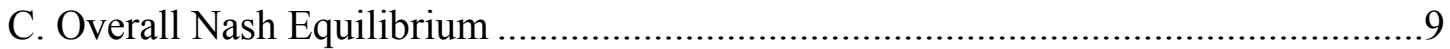

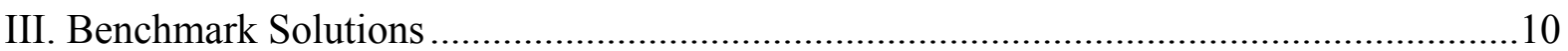

A. Benchmark 1: Optimized World Welfare ........................................................ 10

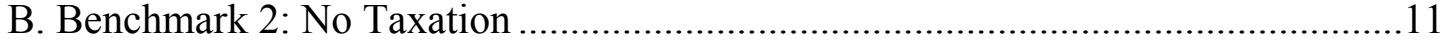

IV. Stackelberg Solution with Importers as Leader ........................................................ 11

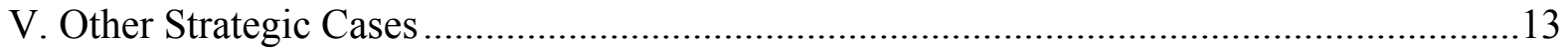

A. Quantitative Importer Targets with No Exporter Taxes .......................................13

B. Importer Output Targets with Optimal Exporter Taxes .........................................14

C. Exporters Set Both Output Price and Quantity ....................................................15

VI. Conclusions and Discussion .............................................................................. 16

Tables

1. Oil Production and Consumption by Major Regions, 2003 ..........................................19

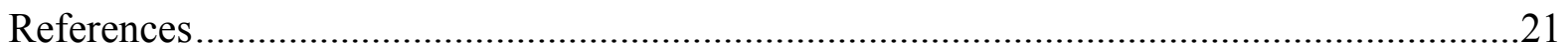




\section{INTRODUCTION}

This paper deals with the following questions: What levels of petroleum taxes would countries consuming (and importing) petroleum, and countries producing (and exporting) petroleum, choose to set, in a world with full separation between consumer and producer countries, full coordination of strategies within each of the two groups, but no coordination between the groups? And, what is the relative advantage of setting a tax versus setting a quota (as part of a "cap-and-trade" solution), in reducing petroleum demand? Policies to limit petroleum consumption are a highly relevant, but controversial, issue today, perhaps most so in the context of greenhouse gas emissions control. ${ }^{2}$ Some countries, including the United States, currently see less need for international coordination of such policies; while Europe and Japan are more proactive, in particular through their efforts to limit emissions under the Kyoto Protocol. While fossil-fuels taxes here yet play a small role, future cooperation on climate policy design is likely to include them in some form.

A "geo-political" model perspective, with a clash of interests between petroleum importers and exporters, is also arguably relevant. The OECD countries and the high-growth Asian economies are large importers; OPEC and the former Soviet Union large exporters. Key interests in this market are, for importers, that exporters do not pursue policies that limit supply; for exporters, that importers do not pursue policies that limit demand. Within the exporting block, OPEC already provides a high degree of exporter coordination, which may be strengthened if importers find it advantageous to cooperate in setting petroleum taxes. No similar cooperation is found on the demand side, but may become reality if and when the main fossil-fuel consuming countries initiate more serious and comprehensive action to limit greenhouse gas emissions.

Given that petroleum consumer and producer countries are two separate groups, petroleum taxes play two main roles. One is to correct for global externalities caused by carbon emissions. ${ }^{3}$ In a united world where producers and consumers of petroleum are one, the optimal worldwide tax is Pigouvian, i.e., equals the global marginal emission cost. ${ }^{4} \mathrm{~A}$ second, strategic, motivation for taxing petroleum however enters when importers and exporters have conflicting interest. As a general principle, when consumer countries tax more, a greater share of petroleum market rent goes to these countries and a smaller share to producer countries; and vice versa when producer countries tax more.

\footnotetext{
${ }^{2}$ The paper has less directly to say about the issue of taxing other fossil fuels, coal and natural gas. These markets fit less well with the model studied here: coal, used largely in electricity generation, is more costly to transport and tends to be consumed much more in the producer country; and natural gas often involves long-run price contracts due to heavy specific infrastructure investments in pipelines.

${ }^{3}$ We are here ignoring the local externalities caused by petroleum consumption, which can in principle be corrected for by taxes and regulations in the countries themselves.

${ }^{4}$ This obviously abstracts from the practical problem of agreeing on what is the correct value of the externality. This is difficult both due to great intrinsic uncertainty and because most benefits of carbon emission control will accrue to future, as of yet unborn, generations. We here also abstract from problems due to the environmental problem being due to a stock externality, while emissions are a current flow.
} 
Two key results are derived from this analysis, and discussed further in the final section of the paper. The first is that, when each of the groups of importers and exporters of fossil fuels acts in a unified way in setting a petroleum tax, but the two groups do not cooperate, each will set a positive tax, and the sum of taxes will be socially excessive (in exceeding the Pigou level). The reason is the pressure for each of the sides to tax, for two separate reasons: one, to counteract externalities from emissions, and a second, to act strategically in order to extract rent from the other party.

The second main result is that, for the importer, it is more favorable to set an optimal tax than to set an optimal quota. The reason is that when the importer sets a quota, and no tax, it puts the exporter in a stronger strategic position, and encourages it to set a higher tax than otherwise. A larger fraction of rents thus accrues to the exporter, when quotas (under a "capand-trade" arrangement) are used, relative to when importer taxes are used.

In the model presented in Section II below, we assume that petroleum is demanded and supplied by atomistic agents, and that demand and supply functions are both linear in price. Petroleum supply is then no direct instrument of policy for petroleum-exporting countries, but instead reacts to price signals. ${ }^{5} \mathrm{We}$ first consider individually optimal tax setting, first by (a cartel of) consumer/importer countries, and then by (a cartel of) producers; in each case taking the tax set by the other party as exogenous. On this basis we derive the overall Nash equilibrium (NE), where importer and producer taxes are simultaneously determined. This solution is compared to two benchmarks, in Section III: the welfare-optimizing tax from a global viewpoint; and no taxation at all. Section IV studies Stackelberg solutions where one party (here, the importer) is leader and the other follower. In Section V we consider two alternative solutions: quantity setting by importing countries (corresponding to a chosen emissions quota for greenhouse gases); and the exporter as a "strong monopolist" setting petroleum price and output independently. Section VI sums up the analysis, and draws conclusions.

In most of the existing literature on petroleum taxation, environmental and strategic motivations are considered separately. Much of the literature considers petroleum as a nonrenewable resource, with competitive price time path subject to Hotelling's (1931) rule. Dasgupta and Heal (1979) showed that a proportional tax on the resource rent (with no extraction costs, the resource price) then has no effect on the optimal extraction profile of producers. Newbery (1976), and later Karp and Newbery (1991a, b), showed that the solution can be complex and involve time inconsistency problems where an announced plan for taxes is not credible. ${ }^{6}$ Taxing petroleum for environmental purposes is studied in general equilibrium models e g by Jorgenson, Slesnick and Wilcoxen (1992), Nordhaus (1993) and Nordhaus and Yang (1996); and with exhaustibility considerations added, by Sinclair (1992,

\footnotetext{
${ }^{5}$ This of course ignores the specifics of considering petroleum an exhaustible resource; see Newbery (2005) and the discussion below.

${ }^{6}$ See also Newbery (2005), who also derives estimates of optimal tariffs on petroleum, under different assumptions about price elasticities of demand for petroleum.
} 
1994) and Ulph and Ulph (1994, 1997). The latter papers find the optimal petroleum tax to be either higher or lower than the Pigou level, and increasing or falling over time. Ulph and Ulph (1994) argue that the tax is likely to fall when the price path nears the backstop price. Farzin (1996), Hoel and Kverndokk (1996), and Strand (2007) however show that as long as marginal extraction cost is upward rising (and resource exhaustion is "economic" rather than physical), and extraction is competitive, the globally optimal emissions tax is Pigouvian along the entire extraction path. Hoel (1996) and Rosendahl (2004) show that optimal carbon taxes may differ across countries and sectors, due to trade and technological considerations. Keen and Strand (2006) show that the optimal tax mix comprises both an ad valorem tax (on goods utilizing fossil fuel inputs) and a specific fuel tax, with weights depending e $g$ on governments' revenue concerns versus their externality concerns. A recent focus is on interactions between fossil-fuel taxation and innovation to abate carbon emissions. Goulder and Mathai (2000) show that the optimal tax is then likely to be rising over time.

Fewer contributions consider environmentally-motivated taxation as a strategic instrument for consumer countries. Markusen (1975) considers strategic importer taxation of a polluting product, and shows that the optimal tax rule consists of a Pigouvian and an import tariff component. Bergstrom (1982) considers strategic non-cooperative tax setting by independent petroleum importing countries, facing either a competitive petroleum supply or a monopoly exporter, and considers petroleum as an exhaustible resource, while ignoring extraction and environmental costs and exporter taxes. ${ }^{7}$ Bergstrom finds that the full burden of an importer excise tax then tends to fall on the exporter. ${ }^{8}$ Finally, Rubio and Escriche (2001) and Liski and Tahvonen (2004) study fossil-fuel taxation in dynamic games between exporting and importing petroleum cartels. ${ }^{9}$ In Liski and Tahvonen, the optimal importer tax consists of a full Pigou tax plus an import tariff element, and thus, as here, an overall tax that is generally higher than the Pigou level. The concluding section contains a further discussion of the relationship between the Liski and Tahvonen model, and ours.

\section{NASh Equilibrium Importer Petroleum TaXes}

\section{A. The Importer Solution}

Consider a petroleum market where demanding countries do not supply and supplying countries do not demand petroleum. Demanding countries behave as a cartel (or monopsonist), agreeing on an importer petroleum tax to maximize utility for the entire group

\footnotetext{
${ }^{7}$ Bergstrom however does consider the strategic relationship between taxes set by importers and a monopolistic exporter, thus leading up to an analysis akin to ours in section 5.3 below.

${ }^{8}$ This result is largely due to the combined assumptions of exhaustibility and zero extraction cost, which leads to a shift in the equilibrium future price path for the resource when an importer tax is imposed. By contrast, extraction costs here play a key role, while exhaustibility does not.

${ }^{99}$ Other early related contribution is Geroski, Ulph and Ulph (1987), who consider market power (by OPEC) explicitly; and. Zhang (1997) who studies producer petroleum taxes to extract maximum rent.
} 
of demanders. We concentrate on an example where utility from petroleum consumption can be aggregated and taking a simple quadratic form in world petroleum consumption, $\mathrm{R}:{ }^{10}$

$$
W_{1}=R-\frac{1}{2} \gamma R^{2}-p R-c_{1} R,
$$

$\gamma$ is a positive coefficient, $\mathrm{p}$ the import price of petroleum, and $\mathrm{c}_{1}$ the negative (climaterelated) externality associated with petroleum consumption for importing countries. ${ }^{11}$ Assume that petroleum has supply function

$$
p=p_{0}+s+\phi R
$$

where $\phi>0$ represents the (inverse) supply sensitivity of petroleum. ${ }^{12} \mathrm{~s}$ is the unit producer petroleum excise tax. $\mathrm{p}_{0}+\mathrm{s}>0$; thus the supply elasticity is less than unity. ${ }^{13} \mathrm{p}_{0}$ is a minimum price below which no petroleum is supplied. The petroleum import tax is $t$, and the consumer price $\mathrm{p}+\mathrm{t}$. Petroleum is imported by small competitive agents, taking prices and overall carbon emissions as given. ${ }^{14}$ The worldwide public demanding petroleum is considered to maximize

$$
V_{1}=R-\frac{1}{2} \gamma R^{2}-(p+t) R
$$

with respect to $\mathrm{R}$, yielding the first-order condition ${ }^{15}$

$$
R=\frac{1-p-t}{\gamma}
$$

\footnotetext{
${ }^{10}$ This assumption in effect embeds additional assumption that will not be discussed further here; in particular, all consumers of petroleum, in all consumer countries must be facing a uniform petroleum price, and all must behave atavistically in their respective markets. We are also, equally heroically, disregarding all distributional concerns, within or between countries.

${ }^{11}$ When $\mathrm{c}_{1}$ represents the greenhouse-gas (GHG) related damage, it will typically involve a stock externality, as there will be an externality cost due to current emissions for all future periods. Such an interpretation of $\mathrm{c}$ is here permissible given that climate effects are linear in emissions, and with an infinite horizon and constant interest (and discount) rate. Then, in addition, damages from future emissions will be independent of the stock of accumulated GHG emissions, at any given time.

${ }^{12}$ The supply function (2) will be derived in subsection 2.2 below.

${ }^{13}$ This follows when $\mathrm{p}_{0}>0$, and $\mathrm{s}>0$ at the optimal solution for exporters, as will be discussed further in the next subsection.

${ }^{14}$ With $\mathrm{n}$ countries and $\mathrm{N}$ demanders of fossil fuels in each country, the externality effect to each demander, as a result of ones own demand for fossil fuels, will be of the order $\mathrm{c} / \mathrm{nN}$, which vanishes when $\mathrm{N}$ is large.

${ }^{15}$ Note that there are no income effects on petroleum demand in this model, following from the assumption that the utility of petroleum consumption, from function (3), is independent of income.
} 
Solving (2) and (4) for R and p yields

$$
\begin{gathered}
R=\frac{1-p_{0}-s-t}{\gamma+\phi} \\
p=\frac{\gamma}{\gamma+\phi}\left(p_{0}+s\right)+\frac{\phi}{\gamma+\phi}(1-t) .
\end{gathered}
$$

Assume that an authority representing all importing countries sets $t$ to maximize $\mathrm{W}_{1}$ in (1), given the private-sector response represented by (5)-(6). This yields the first-order condition

$$
\frac{d W_{1}}{d t}=\left(1-\gamma R-p-c_{1}\right)\left(-\frac{1}{\gamma+\phi}\right)+R \frac{\phi}{\gamma+\phi}=0
$$

Inserting for $\mathrm{R}$ and $\mathrm{p}$, we derive the following optimal importer tax:

$$
t=\frac{\gamma+\phi}{\gamma+2 \phi} c_{1}+\frac{\phi}{\gamma+2 \phi}\left(1-p_{0}-s\right) \text {. }
$$

$t$ is a weighted sum of the marginal externality cost of fossil-fuel consumption for importers, $\mathrm{c}_{1}$, and the net maximum rent from fossil fuels for importers, $1-\mathrm{p}_{0}-\mathrm{s}$, with greater weight to the former. The second term represents non-competitive importer behavior, and is greater when $\phi$ is higher (a relatively smaller supply response to an increase in the producer price; and thus a high ability of importers to affect this price).

The optimal $\mathrm{W}_{1}$ is:

$$
W_{1}=\frac{1}{2(\gamma+2 \phi)}\left(1-p_{0}-s-c_{1}\right)^{2} .
$$

$\mathrm{W}_{1}$ decreases in s; i.e., higher petroleum taxation by producer countries lowers maximized utility (including the negative externality from carbon emissions) for consumer countries. Clearly, consumer countries prefer producers to set a low petroleum tax.

When $c_{2}=0$, all negative externalities are suffered by the consuming countries. We must then obviously have $1-\mathrm{p}_{0}>\mathrm{c}_{1}$ : otherwise petroleum would not be an economically meaningful good. ${ }^{16}$ Then given $\mathrm{s}=0$, from (8) $\mathrm{t}>\mathrm{c}_{1}$ : The Nash equilibrium importer petroleum tax, given no producer tax, always exceeds the importer Pigou tax.

\footnotetext{
${ }^{16}$ In more realistic cases, the demand function is linear only as an approximation in the neighborhood of equilibrium, and not globally. The condition, under which t exceeds the Pigou level, is then that the value of the first petroleum unit as calculated from the linearized demand function, exceed the marginal externality cost; which will also hold unless $\mathrm{c}_{1}$ is extremely large.
} 


\section{B. The Producer Solution}

Consider a single producer country with welfare function

$$
W_{2}=\Pi_{2}+s R-c_{2} R,
$$

where $\Pi_{2}$ is net profits of petroleum producers, $\mathrm{sR}$ is income from the producer excise tax, and $c_{2} R$ negative externalities from carbon emissions for the exporter. $c_{2}$ may be small relative to $\mathrm{c}_{1}$, as exporters, not consuming petroleum, should comprise a small share of the global population. Net profits of producers are

$$
\Pi_{2}=(p-s) R-p_{0} R-\frac{1}{2} \phi R^{2} .
$$

Maximizing (11) with respect to R yields the producer supply function (2). The producer country government maximizes $\mathrm{W}_{2}$ with respect to $\mathrm{s}$, taking (2), the price relation (6), and $\mathrm{t}$ as given. The first-order condition for this problem is

$$
\frac{d W_{2}}{d s}=\left(p-p_{0}-\phi R-c_{2}\right)\left(-\frac{1}{\gamma+\phi}\right)+R \frac{\gamma}{\gamma+\phi}=0,
$$

which yields the optimal $R$ in this case:

$$
R=\frac{p-p_{0}-c_{2}}{\gamma+\phi}
$$

(2), (6) and (13) solve for R, p and s, taking $\mathrm{t}$ as exogenous. The solution for $\mathrm{s}$ is

$$
s=\frac{\gamma}{2 \gamma+\phi}\left(1-p_{0}-t\right)+\frac{\gamma+\phi}{2 \gamma+\phi} c_{2}
$$

Maximized welfare of petroleum producers is (in fashion similar to (9)):

$$
W_{2}=\frac{1}{2(2 \gamma+\phi)}\left(1-p_{0}-t-c_{2}\right)^{2}
$$

Producer utility decreases in the importer-country petroleum tax, t. Like importers, producers wish the other party (here, consumer countries) not to tax petroleum. 


\section{Overall Nash Equilibrium}

Solving simultaneously for s and t from (16) and (8), we find

$$
\begin{aligned}
t & =\frac{(2 \gamma+\phi) c_{1}+\phi\left(1-p_{0}-c_{2}\right)}{2(\gamma+\phi)} \\
s & =\frac{(\gamma+2 \phi) c_{2}+\gamma\left(1-p_{0}-c_{1}\right)}{2(\gamma+\phi)} .
\end{aligned}
$$

$\mathrm{s}$ and $\mathrm{t}$ are both weighted sums of two terms, the externality cost $\left(\mathrm{c}_{1}\right.$ for importers setting $\mathrm{t}$, and $\mathrm{c}_{2}$ for producers setting $\mathrm{s}$ ), and a strategic (or "optimal tariff") component. $\mathrm{s}$ increases in $\mathrm{c}_{2}$ and falls in $\mathrm{c}_{1}$, and vice versa for $\mathrm{t} . \mathrm{s}$ falls in $\mathrm{c}_{1}$ since $\mathrm{s}$ falls in $\mathrm{t}$ (from (16)), and higher $\mathrm{c}_{1}$ raises $t$. Intuitively, when $t$ increases, there is less to gain for the exporter by raising taxes as there is less net rent to be extracted per unit of tax; the same holds for the importer when $\mathrm{s}$ increases.

As for the second (strategic) component, $\mathrm{s}$ is affected relatively more by strategic factors when $\gamma$ is greater (petroleum demand is relatively insensitive to price, by (4)), while $t$ is affected more when $\varphi$ is greater (petroleum supply is insensitive to price, by (2)).

Adding s and t from (16)-(17), we have the following result:

Proposition 1: In non-cooperative NE for importer and producer petroleum taxes, the total petroleum tax $z=s+t$ exceeds the Pigou level, and is given by

$$
z=\frac{1}{2}\left(c_{1}+c_{2}+1-p_{0}\right)
$$

In our simple linear case, $\mathrm{z}$ is half of aggregate externalities plus $1-\mathrm{p}_{0}$ (the difference between maximum demand price 1 , and minimum supply price $\mathrm{p}_{0}$; equal to net willingness to pay for the first unit of petroleum consumption). Since $1-\mathrm{p}_{0}>\mathrm{c}_{1}+\mathrm{c}_{2}$, $\mathrm{z}$ must exceed the Pigou level.

Solutions for producer price $\mathrm{p}$, petroleum output $\mathrm{R}$, importer and exporter welfare, $\mathrm{W}_{1}$ and $\mathrm{W}_{2}$, and aggregate world welfare, $\mathrm{W}=\mathrm{W}_{1}+\mathrm{W}_{2}$, are

$$
\begin{gathered}
p=\frac{1}{2}\left(1+p_{0}-c_{1}+c_{2}\right) \\
R=\frac{1-p_{0}-c_{1}-c_{2}}{2(\gamma+\phi)} \\
W_{1}=\frac{\gamma+2 \phi}{8(\gamma+\phi)^{2}}\left(1-p_{0}-c_{1}-c_{2}\right)^{2} \\
W_{2}=\frac{2 \gamma+\phi}{8(\gamma+\phi)^{2}}\left(1-p_{0}-c_{1}-c_{2}\right)^{2}
\end{gathered}
$$




$$
W=W_{1}+W_{2}=\frac{3}{8} \frac{\left(1-p_{0}-c_{1}-c_{2}\right)^{2}}{\gamma+\phi} .
$$

With NE tax setting, welfare of the two blocks is affected very similarly by changes in the externalities $\mathrm{c}_{1}$ and $\mathrm{c}_{2}$; but more differently by changes in the response parameters $\phi$ and $\gamma$, importers (exporters) being more affected by export supply (import demand) responses.

\section{BENCHMARK SOLUTIONS}

\section{A. Benchmark 1: Optimized World Welfare}

A benchmark for comparing the above solution is one where a unified world government sets petroleum taxes to maximize world welfare. World welfare given by

$$
W=R-p_{0} R-\frac{1}{2} \gamma R^{2}-\frac{1}{2} \phi R^{2}-c_{1} R-c_{2} R,
$$

is then maximized with respect to $\mathrm{R}$, yielding

$$
R=\frac{1-p_{0}-c_{1}-c_{2}}{\gamma+\phi} .
$$

Invoking (5) (which still holds when all producers and consumers of petroleum act competitively), the optimality condition for the aggregate petroleum tax can be expressed as

$$
z=c_{1}+c_{2},
$$

which is, of course, the Pigouvian tax. The split of the overall petroleum tax, between a producer-country tax (s) and a consumer-country tax (t), is arbitrary in implementing the efficient solution.

With non-cooperative NE tax setting by each group of consumers and producers, the "Pigou aspect" of the tax is reduced to exactly half. NE taxes however serve an additional rentextraction purpose for the respective governments, contributing to an overall NE tax in excess of the Pigouvian level.

Maximized aggregate world welfare is

$$
W=\frac{\left(1-p_{0}-c\right)^{2}}{2(\gamma+\phi)},
$$

where $\mathrm{c}=\mathrm{c}_{1}+\mathrm{c}_{2}$. Comparing (27) to (23), aggregate welfare in the (excessive-tax) NE case equals exactly $3 / 4$ of maximized welfare. 


\section{B. Benchmark 2: No Taxation}

A second benchmark is the no-tax case. Fossil-fuel consumption and price, $\mathrm{R}$ and $\mathrm{p}$, are then given by (4)-(5) setting $\mathrm{s}=\mathrm{t}=0$. Aggregate welfare of importers and producers is

$$
W=W_{1}+W_{2}=\frac{1}{2} \frac{\left(1-p_{0}-2 c\right)\left(1-p_{0}\right)}{(\gamma+\phi)}
$$

Aggregate welfare is now lower than with optimal taxation. Denoting optimal welfare (from (27)) by $\mathrm{W}(*)$, and welfare in the current case by $\mathrm{W}(0)$, respectively, the loss is

$$
W(*)-W(0)=\frac{c^{2}}{2(\gamma+\phi)},
$$

proportional to the square of the externality, and thus a standard "Harberger triangle" loss. A more interesting welfare comparison is between no taxes and the non-cooperative Nash case. With welfare $\mathrm{W}(\mathrm{N})$ in the NE case (from (23)), we find

$$
W(N)>W(0) \Leftrightarrow c>\frac{2}{5}\left(1-p_{0}\right) .
$$

In our particular linear example, only when the aggregate externality cost is above this particular threshold is aggregate world welfare greater in the NE solution than with no tax. This threshold can be high; $1-p_{0}$ is society's net valuation of the first unit of petroleum consumed. The world society might then be better off with no fossil-fuel taxation, if the alternative is non-cooperative consumer-producer NE taxation.

On the other hand, given that one party does not tax, it is always beneficial for the other party to tax at least to some degree, both in a social (potential Pareto) sense and privately. When producer countries do not tax petroleum, the optimal consumer-country tax is given by (8) (with $\mathrm{s}=0$ ). The welfare gain from such a unilateral optimal tax equals

$$
W(N ; 0)-W(0)=\left(\phi\left(1-p_{0}\right)+(\gamma+\phi) c_{1}\right)^{2},
$$

which is always positive.

\section{STACKELBERG SOLUTION WITH IMPORTERS AS LEADER}

In some cases, the tax setting game may be better viewed as not played out simultaneously, but instead with one party as natural leader, e $\mathrm{g}$ because it is first in establishing a tax policy. The other party may then need to react to the leader's policy, in setting its tax. One then needs to consider Stackelberg solutions, with either the petroleum importer or exporter group as leader. We formally analyze only the importer-country leadership case; the case with the exporter as the first mover is parallel. 
As in the NE case, the exporter tax is given by (16), where $t$ is taken as given by the exporter in setting $\mathrm{s}$. The importer however now takes not $\mathrm{s}$, but rather the schedule (16), providing a reaction function of $s$ to the setting of $t$, as given. The first-order condition for the importer is then:

$$
\frac{d W_{1}}{d t}=\left(1-\gamma R-p-c_{1}\right)\left(-\frac{1}{\gamma+\phi}\right)+R\left(\frac{\gamma}{2 \gamma+\phi}+\frac{\phi}{\gamma+\phi}\right)=0
$$

which yields

$$
R=\frac{2 \gamma+\phi}{(3 \gamma+\phi)(\gamma+\phi)}\left(1-p-c_{1}\right)
$$

(33), (2), (5) and (14) now solve for R, p, s and t. For t and s we find:

$$
\begin{gathered}
t=\frac{(2 \gamma+\phi)^{2}}{(\gamma+\phi)(5 \gamma+2 \phi)} c_{1}+\frac{(\gamma+\phi)^{2}+\gamma \phi}{(\gamma+\phi)(5 \gamma+2 \phi)}\left(1-p_{0}-c_{2}\right) \\
s=\frac{(\gamma+\phi)(5 \gamma+2 \phi)-\gamma(2 \gamma+\phi)}{(\gamma+\phi)(5 \gamma+2 \phi)} c_{2}+\frac{\gamma(2 \gamma+\phi)}{(\gamma+\phi)(5 \gamma+2 \phi)}\left(1-p_{0}-c_{1}\right) .
\end{gathered}
$$

To compare with the NE case, we compare the coefficient before the last term in (34) to the corresponding coefficient in (16). The former is greater, implying that $\mathrm{t}$ is greater, and $\mathrm{s}$ lower, in the Stackelberg case. Intuitively, the leader (importers) uses its strategic advantage to set a higher tax, thus inducing the follower (producers) to set a lower tax (since taxes are strategic substitutes); this is advantageous for the leader as its utility is a decreasing function of the follower's tax.

The following main result emerges in this case:

Proposition 2: When the importer is Stackelberg leader in setting taxes, and the exporter is follower, the overall tax $z$ is higher than in the NE case, and given by

$$
z=s+t=\frac{2 \gamma+\phi}{5 \gamma+2 \phi} c+\frac{3 \gamma+\phi}{5 \gamma+2 \phi}\left(1-p_{0}\right)
$$

This result follows as $\mathrm{z}$ is still a weighted sum of $\mathrm{c}\left(=\mathrm{c}_{1}+\mathrm{c}_{2}\right)$ and $1-\mathrm{p}_{0}$, but now with greater weight to $1-\mathrm{p}_{0}$. Intuitively, consider consumer countries, first, setting $t$ unilaterally, higher than the Nash level in (16). Producer countries react to this by reducing their tax, s, below the Nash level; but by less than the initial increase in t. Petroleum output is

$$
R=\frac{2 \gamma+\phi}{(5 \gamma+2 \phi)(\gamma+\phi)}\left(1-p_{0}-c_{1}-c_{2}\right)
$$


lower than in the simultaneous NE case.

The Stackelberg solution with producers as leaders is easily found to be parallel, with the two parties in opposite roles. E g, the formula for the aggregate tax, $\mathrm{z}$, is as in (36) only with $\gamma$ and $\varphi$ switching places; and the producer tax is higher, and the consumer-country tax lower, than in the Nash case.

Being a leader is advantageous as it permits setting a higher tax than in the NE case, thus inducing the follower to set its tax below the NE level.

\section{Other Strategic Cases}

In this section we consider three additional cases. In the first two, the importer chooses a quantitative target for petroleum consumption, instead of a tax, corresponding to an importercountry carbon emissions target. This regime is implemented by a system of tradable emission quotas initially auctioned among importing-country emitters. The main scheme for controlling carbon emissions under the Kyoto Protocol, the European Union emissions trading scheme, EU ETS, is of this general type, albeit with some differences. ${ }^{17}$ We first assume that exporters impose no petroleum taxes. Next, we assume that the exporter responds to the quantitative scheme by setting optimal ad valorem export taxes.

In the last additional case, the exporter behaves as a "strong cartel", by fixing the export price of petroleum, and supplying exactly an amount necessary to fulfill demand at this price. The exporter is then not constrained by any petroleum supply function; supply is dictated directly e $\mathrm{g}$ following from production being directly under government control.

\section{A. Quantitative Importer Targets with No Exporter Taxes}

Here it is optimal for the importing country government to set the quota equal to the optimal solution for $\mathrm{R}$ from section II A given $\mathrm{s}=0$, which is found as

$$
R(Q ; 0)=\frac{1}{\gamma+2 \phi}\left(1-p_{0}-c_{1}\right) .
$$

Licenses to buy R (or emit the corresponding carbon amount) are assumed to be auctioned off among demanders. The equilibrium auction price, $\mathrm{q}(0)$, will then equal the tax derived from (8):

$$
q(0)=\frac{\gamma+\phi}{\gamma+2 \phi} c_{1}+\frac{\phi}{\gamma+2 \phi}\left(1-p_{0}\right)
$$

\footnotetext{
${ }^{17}$ A main difference is the current lack of auctioning of emission permits under EU ETS, with 95 percent of emission rights being given away to firms for free. Another difference is that the EU ETS only comprises a fraction (less than half) of carbon emissions in the European Union.
} 
The importer government's quota sales revenue must equal the tax revenue from optimal importer taxes in section II A. Thus, the solutions are identical, and both are optimal from the point of view of importing countries. They also yield the same income for government, in the former case through the importer excise tax on petroleum; in the current case, by auctioning off quotas costing the same as the tax.

\section{B. Importer Output Targets with Optimal Exporter Taxes}

Exporters here set their petroleum tax optimally. Assume that the quota chosen by importers equals $R(Q)$. Importers then never buy more petroleum than $R(Q)$, implying that supply will never exceed this level. Consider two sub cases: a) petroleum supply equals $R(Q)$; and $b)$ petroleum supply is less than $\mathrm{R}(\mathrm{Q})$.

In case a, exporter countries prefer petroleum output to equal at least $R(Q)$. With no importer taxes $(\mathrm{t}=0)$, the exporter would ideally produce $\mathrm{R}(0)$ given by

$$
R(0)=\frac{1-p_{0}-c_{2}}{2 \gamma+\phi}
$$

Given $\mathrm{R}(\mathrm{Q}) \leq \mathrm{R}(0), \mathrm{R}(\mathrm{Q})$ will be the realized output (since the exporter would not voluntarily choose a lower level). (5) (with $\mathrm{t}=0$ ) must still hold, since importer-country petroleum demand must be exactly realized at equilibrium; and since exporters will set the highest possible level of s corresponding to such an equilibrium. $\mathrm{s}$ will be given by

$$
s=1-p_{0}-(\gamma+\phi) R(Q),
$$

set to exactly clear the petroleum market in importer countries. As a result, the equilibrium price in the quota market in importer countries equals zero.

In deriving $\mathrm{R}(\mathrm{Q})$, the importer knows that $\mathrm{s}$ will be adjusted to its highest possible level for any given $\mathrm{R}(\mathrm{Q})$, from (40). The output price faced by the importer will depend on the import target set, and equal

$$
p=1-\gamma R(Q)
$$

To derive $R(Q)$ (within the restriction $R(Q) \leq R(0)$ ), importers maximize (1) with respect to $\mathrm{R}(\mathrm{Q})$, taking $\mathrm{p}$ as given from (41). The resulting expression for importer welfare, $\mathrm{W}_{1}$, is

$$
W_{1}=\frac{1}{2} \gamma(R(Q))^{2}-c_{1} R(Q)
$$

$\mathrm{W}_{1}$ is here strictly convex in $\mathrm{R}(\mathrm{Q})$, implying that importers wish to set $\mathrm{R}(\mathrm{Q})$ either at zero (i.e., consume no petroleum), or at its highest possible level given $R(Q) \leq R(0)$. Disregarding the former case, $R(0)$ will be optimal for importers. Importer-country utility is now the same 
as with $\mathrm{t}=0$ and $\mathrm{s}$ given from (16), and lower than in Section II above. Since the exporter chooses to never to restrict $R$ to a level less than $R(0)$, case a) above is always valid.

We have thus just shown the following interesting result:

Proposition 3: Assume that the importer sets a fixed import quota for petroleum, while the exporter sets an optimal petroleum tax. The solution is then the same as in the case of a zero importer tax. The exporter tax, petroleum output and exporter utility will all be higher, and the aggregate tax and importer utility lower, than in the NE case.

Intuitively, it makes a great strategic difference whether the importer sets a petroleum tax (or price) or a quota (a quantitative instrument). When the importer is perceived by the exporter to set a quota, petroleum demand is perceived as perfectly inelastic to price (for prices not exceeding the clearing price of petroleum). This in turn gives the exporter maximal monopoly power to set its tax and thus price, driving it up to the level that eliminates net rents at the margin for importer-country consumers. This basic argument can be shown to hold also when moves are simultaneous.

In conclusion, a quantitative constraint is less attractive than a tax for importer countries, given that exporters impose an optimal export tax on petroleum in response to the quantitative constraint. This holds even though the petroleum (or carbon) tax is replaced by a system of quota trading that, presumably, mimics the tax scheme. The difference lies in the strategic behavior of the seller, which is more aggressive in the quantitative case than in the tax case, thus setting a higher exporter tax in the former case. In response, the importer can do no better than impose a quota corresponding to a zero tax, with lower utility to the importer than if the importer had set and optimal tax.

The solution in this case, with R given by (39), may still be closer to the overall efficient petroleum consumption level, (25), than the Nash solution with simultaneous tax setting, given by (20). Indeed this is likely; we may even have as a special case that $\mathrm{R}$ now equals the optimal level, something that was not possible in the Nash case: it holds when

$$
c_{1}=\frac{\gamma}{2 \gamma+\phi}\left(1-p_{0}-c_{2}\right)
$$

This is a possibility when $\varphi$ is large relative to $\gamma$. When $\mathrm{c}_{1}$ is lower than this level, $\mathrm{R}(0)$ is sub-optimal; in the opposite case it is too high.

\section{Exporters Set Both Output Price and Quantity}

In this final case, the exporter group sets petroleum export price and output directly. This implies a "stronger" exporter policy than in Section II above. The exporter now directly controls all aspects of policy, setting $p$, and supplying whatever output necessary to sustain this price. The importer now sets $t$, as in Section II. 
We consider two variants of this strategy. The first is the NE case where all variables are determined simultaneously. Note first that, for given $\mathrm{t}$, the optimal $\mathrm{R}$ for the exporter, with an associated clearing price $\mathrm{p}$, is still given by (18). The relationship between $\mathrm{p}$ and $\mathrm{R}$ is determined from (4) since, once $\mathrm{R}$ and $\mathrm{t}$ are given, (4) determines the clearing price $p .{ }^{18}$ To determine $t$, the importer maximizes (1) with respect to $R$, taking $p$ as a constant. This yields

$$
R=\frac{1-p-c_{1}}{\gamma}
$$

assuming that this is feasible ( $\mathrm{R}$ from (43) cannot exceed the exported quota). Since (4) must still hold, $\mathrm{t}=\mathrm{c}_{1}$, implying that the importer tax is Pigouvian. From (2), (6) and (13), the solution for $\mathrm{R}$ is then given by

$$
R=\frac{1-p_{0}-c_{1}-c_{2}}{2 \gamma+\phi}
$$

$\mathrm{R}$ is now higher than in the simultaneous NE case, in section II, since $\mathrm{t}$ is set lower. The strategic motivation for taxing petroleum is now removed from the importer, who instead applies a Pigou tax. The utility of the exporter is also higher.

When the exporter is a Stackelberg leader in setting $\mathrm{p}$ and $\mathrm{R}$, the solution is the same as in the simultaneous Nash case. This follows because $t$ is the same (in both cases Pigou, since $t$ does not depend on any aspect of exporter policy). For given t, the optimal exporter action is unique.

In the second variant, the importer is a Stackelberg leader in setting $t$ before the exporter sets price and output. Now the exporter must take $t$ as given in setting its petroleum output $R$, and we are back to the Stackelberg solution derived in Section IV. There is then nothing to gain for the exporter by having the ability to set $\mathrm{p}$ and $\mathrm{R}$ independently, instead of setting an export tax as in section $4 .{ }^{19}$

\section{Conclusions ANd Discussion}

We have in this paper analyzed a model where the countries consuming and producing petroleum are fully separated, each group operates as a unified tax-setting block, and the two blocks do not cooperate. Section II studies a non-cooperative Nash game between the two blocks, where each block sets an optimal excise tax of petroleum. Each tax is then found as a

\footnotetext{
${ }^{18}$ Another way to put this is to say that the exporter will always charge the highest price at which the total quantity of R would be sold to importers; this must be optimal for the exporter, since otherwise it would have selected a lower level of R.

${ }^{19}$ Note that, also in this case of a "strong monopolist" that has the ability to set both output and price, but where the importer is a Stackelberg leader, it makes a great strategic difference for the importer whether he sets a quota or a tax, with preference for the latter.
} 
weighted sum of a term representing externalities of petroleum consumption imposed on that party, and a term representing the party's market monopoly power. This power is positively related to the market (demand or supply) response to prices, for oneself relative to that of the other block. The two taxes are strategic substitutes: When one is increased, the other falls in response. Each block would prefer the other party to set as low a petroleum tax as possible (or better, to subsidize petroleum).

In the Nash Equilibrium (NE), each tax is a weighted sum of two terms: own externalities; and a factor representing own monopoly power. A greater externality suffered by one block of countries raises the equilibrium tax set by this block, and lowers the tax set by the other block. In our particular linear example studied, the aggregate (producer plus consumer) tax is found as half the sum of externalities plus a "monopoly" term, where the latter is always greater than the former term. This has two significant implications. First, when the externality caused by a unit of petroleum consumption increases, the NE tax increases by half as much. Secondly, the NE tax always exceeds the Pigou level. Welfare in the NE is sub-optimal, and possibly lower than with no petroleum tax.

Section IV studies a Stackelberg case where the importer group sets its tax before exporters. The importer tax is higher than in the NE, and the exporter tax lower. The aggregate tax is higher, since the importer's increase is greater than the exporter's reduction. A similar converse case holds when the producer cartel is a Stackelberg leader in tax setting.

In section $\mathrm{V}$ we study additional cases. The first of these is particularly significant. We here assume that the importer sets a quota for petroleum (with a cap-and-trade scheme for consumers), instead of an import tax. The optimal strategy of the exporter is then to set a higher export tax (so high that the importer quota price is optimally set equal to zero ex post). As a result, setting an optimal quota is worse for the importer than setting an optimal tax. Thus given the choice, the importer would always choose a tax scheme instead of a cap-andtrade scheme for implementing a given fossil-fuel consumption. We also show that fossil-fuel consumption, with its related emissions, is greater under a cap-and-trade scheme: while the equilibrium petroleum import price for the importing block will be higher, the equilibrium price to consumers in importing countries will be lower. The intuitive reason for this result is that importers are put in a better strategic position by taxing, as this strategy leads to a direct rent extraction from exporters. No similar rent extraction results from a cap-and-trade policy, given that exporters react optimally to this policy.

In the second case, the producer acts as a "strong monopolist" by fixing the petroleum export price, and exactly satisfying demand at this price. The importer then takes the import price as given and sets a Pigouvian tax, lower than the NE tax. Not surprisingly, such a policy is advantageous for the exporter, and disadvantageous for the importer.

Overall, when importers and exporters of petroleum behave as two optimizing blocks, both parties have incentives to tax petroleum aggressively, with overall taxes exceeding the Pigou level. But the fraction of the tax that is motivated by externalities alone is always less than the Pigou level. The latter conclusion contrasts Rubio and Escriche (2001) and Liski and 
Tahvonen (2004), studying related dynamic models, where the externality component is generally always Pigouvian.

These underlying incentives to tax petroleum, on both sides of the demand-supply relationship, however do not represent actual tax policy for fossil fuels today. There is today no unified policy toward fossil-fuel taxation by major importers, indeed, little taxation at all: the only major (imperfect) examples are motor-fuels taxation in Europe, and the EU-ETS trading scheme for greenhouse gas emissions initiated by European countries' need to abide by GHG emission limitations under the Kyoto Protocol ${ }^{20}$ The latter scheme implies a positive cost of carbon emissions, but the scheme's ability to significantly constrain overall fossil-fuel consumption (and emissions) is questionable. ${ }^{21}$ Our analysis is rather normative, showing that substantial taxation is gainful. For the world, Pigou taxation is optimal. Viewed by the importing countries in isolation, gains go beyond this level.

A key result, from Section $\mathrm{V}$, is that the importer has strict preference for taxes over quotas in limiting its fossil fuels consumption; this consumption will also be lower under optimal taxes than under optimal quotas. This result can be shown to hold more generally, whenever exporters act non-competitively. ${ }^{22}$ It relies on the difference between price (tax) versus quantity (quota) setting as the importer's strategic variable. What may surprise is the simplicity and generality of this result, and the fact that it appears to have been so far ignored in the discussion over taxes versus quantities in climate policy.

The paper relies on a number of sweeping and stylized assumptions, implying that results are in some respects not very general. First, petroleum consuming and producing countries are separated into two separate blocks. While this of course does not hold strictly, it still has some basis in reality (see Table 1), the consuming block comprising largely OECD plus most of Asia, and the producing block consisting of the Middle East, the former Soviet Union, and (a few) countries in Africa and Latin America. Imports by the former block, and exports by the latter, are each about half of world production. Two major importers, the United States and China, both have significant oil production, but large and growing net imports; their main interests are solidly, and increasingly, on the demand side.

A relevant and straightforward extension would be to allow for less than full tax coordination among importers (as e $\mathrm{g}$ in Bergstrom (1982)). This would make importer taxation strategies

\footnotetext{
${ }^{20}$ The EU ETS is, obviously, an example of a quota scheme of the types analyzed in Section V, rather than of a tax scheme in Section II.

${ }^{21}$ There are several problems with the ETS. One of these is the high degree of free allocation of emission quotas to past emitters (at least 95 percent in the current trading period; and at least 90 percent for the 2008-2012 period), providing high windfall gains to emitters and robbing governments of potential tax revenue; see Goulder (2002) and OECD (2004). As argued by Böhringer and Lange (2005) and Rosendahl (2006), perhaps even more damaging is the system's lack of ability to deliver carbon reductions over time, since future free quotas tend to depend on current emissions, and are expected to do so in the future.

${ }^{22}$ The result can rather easily be generalized to the case where exporters do not act as a monopoly but instead in monopsonistic (Nash-Cournot) fashion or as a leader with a competitive fringe.
} 
less aggressive. An issue is whether Pigouvian (or higher) petroleum taxation is then still sustainable in a NE, and the conditions under which this holds.

A better clarification between the current, static, analysis and a dynamic one is also warranted. The supply behavior for petroleum is here modeled as a short-run response to current prices. This fails to capture the effects on supply through expectations about future petroleum prices, considered in the Farzin (1996), Hoel and Kverndokk (1996), Rubio and Escriche (2001), Liski and Tahvonen (2004) and Strand (2007) contributions already cited. On the other hand, the Markov Perfect Nash Equilibrium concept of Rubio and Escriche (2001), Liski and Tahvonen (2004) fails to capture the other party's (demand or supply) response to one party's tax policy, as the opposite party's policy variables are taken as given, and the extraction path not significantly affected by the tax. This feature is responsible for a full Pigouvian externality response in their model (moreover, they do not consider exporter taxes). Further analysis is needed to clarify the relationships between these models.

Table 1. Oil Production and Consumption by Major Regions, 2003

(Million tons)

\begin{tabular}{lcccc}
\hline \multicolumn{1}{c}{ Major Area } & Oil Consumption & Oil Production & Oil Imports & Oil Exports \\
\hline European Union & 621 & 122 & 578 & 87 \\
North America & 808 & 310 & 552 & 50 \\
OECD Pacific & 341 & 24 & 332 & 15 \\
China & 251 & 169 & 91 & 8 \\
Rest Asia & 343 & 152 & 261 & 71 \\
Total, mainly oil & 2364 & 777 & 1814 & 231 \\
importing regions & 180 & 1040 & 18 & 878 \\
Middle East & 130 & 488 & 52 & 410 \\
Former USSR & 97 & 373 & 39 & 315 \\
Africa & 164 & 312 & 57 & 205 \\
$\begin{array}{l}\text { Latin America } \\
\text { Total, mainly oil }\end{array}$ & 571 & 2213 & 166 & 1808 \\
\hline
\end{tabular}

Source: International Energy Agency (2006). 
Our assumption that all petroleum consumers and producers behave competitively, is clearly unrealistic. OPEC represents most large oil exporters (apart from Russia and Norway) and actively attempts to regulate oil supply and pricing. ${ }^{23}$ Bilateral monopoly games between producer and consumer cartels can be complicated; previous analyses of such issues (including Tahvonen (1995), Wirl (1995), Rubio and Escriche (2001) and Liski and Tahvonen (2004)), are however all based on the Markov Perfect Nash Equilibrium concept in continuous time. Overall, the extraction profile is then not substantially affected by the tax; in which case the importer setting the tax has little incentive to let the environmental component deviate from the Pigou level. ${ }^{24}$ In our model by contrast, the environmental component to the tax is lower as both negative demand and supply effects of taxes are considered, giving strategic motivations to charge lower-than-Pigou environment tax components. Note that other solution concepts may also be relevant and warrant future analysis, in particular related to the modeling of pricing and supply strategies by OPEC and other major exporters, explicitly considering oil as an exhaustible resource; and interactions with other energy markets (such as those for boifuels). The equilibrium price level might then conceivably, be well above marginal extraction cost, even when the marginal cost curve is upward sloping. ${ }^{25}$

Our model embeds no uncertainty about externality costs or demand and supply functions. A more satisfactory discussion of tax versus quantitative (cap-and-trade) strategies requires accounting for uncertainty; and consideration of other forms than the linear for demand and supply functions. We intend to come back to such extensions in future work.

\footnotetext{
${ }^{23}$ In recent years OPEC has, arguably, functioned more as an intertemporal regulator of supply than as a general suppressor, or has at least attempted to do so. Over the two years up to October 2006, when demand and price levels remained high, the group has generally not restricted supply. Over the last months there has again been some attempt by OPEC to regulate supply directly, in view of falling equilibrium oil market prices.

${ }^{24}$ A large fraction of oil supply comes from companies that are directly government owned and where supply cannot be assumed to respond to price signals in a regular market-determined way. This raises the important and complicated, and so far unresearched, issue of what would be the exporter supply response from these companies, to petroleum taxes imposed by importer countries.

${ }^{25}$ Note that the classical view of petroleum as an exhaustible resource may be challenged by development of new cost-competitive energy sources, such as biofuels, with the same functions as oil.
} 


\section{References}

Bergstrom, Theodore C., 1982, On Capturing Oil Rent with a National Excise Tax, American Economic Review, 72, pp. 194-201.

Böhringer, Christoph, and Andreas Lange, 2005, On the Design of Optimal Grandfathering Schemes for Emission Allowances, European Economic Review, 49, pp. 2041-55.

Farzin, Y. Hossein (1996), Optimal Pricing of Environmental and Natural Resource Use With Stock Externalities. Journal of Public Economics, 62, pp. 31-57.

Geroski, Paul A., Alistair M. Ulph, and David T. Ulph, 1987, A Model of the Crude Oil Market in Which Market Conduct Varies, Economic Journal, 97, pp. 77-86.

Goulder, Lawrence H., 2002, Mitigating the Adverse Effects of $\mathrm{CO}_{2}$ Abatement Policies on Energy Intensive Industries, Working Paper (Washington: Resources for the Future).

Goulder, Lawrence $\mathrm{H}$. and Koshy Mathai, 2000, Optimal $\mathrm{CO}_{2}$ Abatement in the Presence of Induced Technical Change, Journal of Environmental Economics and Management, 39 , pp. 1-28.

Hoel, Michael, 1996, Should a Carbon Tax be Differentiated Across Sectors? Journal of Public Economics, 59, pp. 17-32.

Hoel, Michael and Kverndokk, Snorre, 1996, Depletion of Fossil Fuels and the Impacts of Global Warming, Resource and Energy Economics, 18, pp. 115-36.

Hotelling, Harold, 1931, The Economics of Exhaustible Resources, Journal of Political Economy, 39, pp. 137-75.

International Energy Agency, 2006, Energy Information Centre: Oil. International Energy Agency, Paris

(http://www.iea.org/Textbase/subjectqueries/keyresult.asp?KEYWORD_ID=4114\#Publicati ons).

Jorgenson, Dale W., Daniel T. Slesnick, and Peter J. Wilcoxen, 1992, Carbon Taxes and Economic Welfare, Brookings Papers on Economic Activity, pp. 393-454.

Karp, Larry and David M. Newbery, 1991a, Optimal Tariffs on Exhaustible Resources, Journal of International Economics, 30, pp. 285-99.

Karp, Larry and David M. Newbery, 1991b, OPEC and the U.S. Oil Import Tariffs, Economic Journal (supplement), 101, pp. 303-13.

Keen, Michael and Jon Strand, 2007, Indirect Taxes on International Aviation, Fiscal Studies, 28, pp. 1-41. 
Liski, Matti and Olli Tahvonen, 2004, Can Carbon Tax Eat OPEC's Rent? Journal of Environmental Economics and Management, 47, pp. 1-12.

Markusen, James R., 1975, International Externalities and Optimal Tax Structures, Journal of International Economics, 5, pp. 15-29.

Newbery, David M., 1976, A paradox in Trade Theory: Optimal Tariffs on Exhaustible Resources. SEER Technical Paper, Department of Economics, Stanford University.

— 2005, Why Tax Energy? Towards a More Rational Policy, The Energy Journal, 26, pp. $1-40$.

Nordhaus, William D., 1993, Optimal Greenhouse-Gas Reductions and Tax Policy in the "DICE" Model, American Economic Review, 83, pp. 313-17. , and Zili Yang, 1996, A Regional Dynamic General-Equilibrium Model of Alternative Climate Change Strategies, American Economic Review, 86, pp. 741-65.

OECD, 2004, Sustainable Policies in OECD Countries, Getting the Policies Right (Paris: Organization for Economic Cooperation and Development).

Rosendahl, Knut Einar, 2004, Cost-Effective Environmental Policy: Implications of Induced Technological Change, Journal of Environmental Economics and Management, 48, pp. 1099-121.

_ 2006, Incentives and Quota Prices in an Emission Trading Scheme with Updating, Working Paper (Statistics Norway).

Rubio, Santiago J., and Luisa Escriche, 2001, Strategic Pigouvian Taxation, Stock Externalities and Polluting Non-renewable Resources, Journal of Public Economics, 79, pp. 297-313.

Sinclair, Peter J. N., 1992, High Does Nothing and Rising is Worse: Carbon Taxes Should Keep Declining to Cut Harmful Emissions, Manchester School, 60, pp. 41-52.

Sinclair, Peter J. N., 1994, On the Optimum Trend of Fossil Fuel Taxation, Oxford Economic Papers, 46, S71-102.

Strand, Jon, 2007, Optimal Taxation of an Exhaustible Resource with Stock Externalities, Backstop Technology and Rising Extraction Cost, unpublished (Washington: International Monetary Fund).

Tahvonen, Olli, 1995, International $\mathrm{CO}_{2}$ Taxation and the Dynamics of Fossil Fuel Markets, International Tax and Public Finance, 2, pp. 261-78. 
Ulph, Alistair M. and David T. Ulph, 1994, The Optimal Time Path of a Carbon Tax, Oxford Economic Papers, 46, pp. 857-68.

- and - 1997, Global Warming, Irreversibility, and Learning, The Economic Journal, 107, pp. 636-50.

Wirl, Franz, 1995, The Exploitation of Fossil. Fuels Under the Threat of Global Warming and Carbon Taxes: A Dynamic Game Approach, Environmental and Resource Economics, 5, pp. 333-52.

Zhang, Lei, 1997, Neutrality and Efficiency of Petroleum Revenue Tax: A Theoretical Assessment, The Economic Journal, 107, pp. 1106-120. 